\title{
Using Twitter to support reflective learning in an asynchronous online course
}

Tian Luo, Smruti J. Shah and Helen Crompton

Old Dominion University, Virginia

\begin{abstract}
The purpose of this study was to further our understanding of the use of Twitter for promoting reflective learning. Specifically, this study investigated how students participate in Twittersupported activities, what types of knowledge are manifested when Twitter is used to reflect on the course readings, and how students perceive the Twitter-supported activities. The data showed that Twitter was successful in keeping the learners engaged in the reflective discussion activities for a prolonged period of time compared to Blackboard. Overall, students had a positive perception towards the integration of Twitter to support reflection and discussion along with active participation. Twitter was effective in increasing perceived learner-content and learner-learner interactivity along with engagement. Additionally, the paper provides recommendations for educational practitioners and discusses directions for future research.
\end{abstract}

\section{Introduction}

Since 2006, Twitter has opened a channel of collaboration that has continued to grow as an educational tool (Tang \& Hew, 2017). Twitter is a microblogging social media tool that allows users to share brief updates for real-time and asynchronous communication consisting of up to 140 characters. The use of Twitter has been adopted and explored by the educational community. The design characteristics of microblogging in $\mathrm{K}-12$, higher education, teacher professional development, industry, business, organisational contexts, and in formal and informal settings have been found to be useful for knowledge construction (Greenhow \& Askari, 2017; Mills \& Chandra, 2011; Pollard, 2014; Ricoy \& Feliz, 2016; Shah, Shabgahi, \& Cox, 2016; Trust, Krutka, \& Carpenter, 2016). In higher education, researchers have used Twitter to extend and enhance the educational experience in various content areas, such as medicine (Bahner et al., 2012), psychology (Blessing, Blessing, \& Fleck, 2012), business (Evans, 2014), electrical engineering and informatics (Ebner, 2009), history (Pollard, 2014), and sociology and anthropology (Welch \& BonnanWhite, 2012). According to a recent systematic review study, Twitter is typically used for five major purposes: assessment, collaboration, administration, reflection, and communication (Tang \& Hew, 2017).

Despite a growing interest in using social media for teaching and learning, research on educational uses is in its burgeoning stage with many questions that have yet to be fully explored (Gao, Luo, \& Zhang, 2012; Tang \& Hew, 2017). While many studies have provided quantitative analysis for using Twitter in the classroom, a more qualitative analysis of the individual student posts is needed to further our understanding of how Twitter is being used in education (Tang \& Hew, 2017). Researchers in the past investigated the use of Twitter for reflecting on teaching practices (Domizi, 2013; Krutka, Nowell, \& Whitlock, 2017; Munoz, Pellegrini-Lafont, \& Cramer, 2014). However, a systematic review of the use of Twitter (Gao et al., 2012; Richardson, Grose, Nelmes, Parra, \& Linares, 2015; Tang \& Hew, 2017), reveals a paucity of research conducted to examine its use for reflecting on the course readings and understanding of the course content specifically, compared to the other existing tools. Therefore, the purpose of this study is to employ a qualitative approach to examine the use of Twitter to reflect on course readings and thereby ameliorate the gap in the existing literature. In this study, Twitter will be compared to the Blackboard discussion board, which is another online discussion tool commonly used in higher education. This paper provides a literature review that briefly introduces readers to Twitter, as well as informs them about its application and educational effects as a pedagogical tool. We also address the significance of comparing Twitter versus Blackboard in this study. We then rationalise our choices for the methodology including data collection and analysis. The results and the discussion sections provide detailed findings for our research questions, and provide practical guidelines and insights for using Twitter to reflect on course content. The conclusion delineates the contributions of the paper and provides recommendations for future research. 


\section{Literature review}

\section{What is Twitter?}

Twitter belongs to the category of microblogging tools that has received empirical consideration due to its ubiquitous, participatory, and interactive nature (Gao et al., 2012; Tang \& Hew, 2017). Microblogging tools afford instant and participatory communication that provide considerable opportunities and allow instructors and designers to meet the disparate needs of various learners. The Pew Research Center's latest report stated that approximately 24\% of all online adults use Twitter (Greenwood, Perrin, \& Duggan, 2016). Twitter has become one of the most popular social networking tools with $36 \%$ of adults ranging from 18 to 29 years of age having an online Twitter presence. Twitter enables its users to publish on the user's profile page, brief text-based contents that are no longer than 140 characters in length. It directly broadcasts and shares the post with all users across the globe (Java, Song, Finin, \& Tseng, 2007). Today, users access Twitter through the website interface, short message service (SMS), or mobile device apps. Twitter also enables users to post multimedia content including graphics and videos that they have recorded using their mobile devices.

To use Twitter, people need to create a Twitter account to establish their unique username. Upon creating an account, users can log into Twitter and can connect with other millions of users. Users can write and post tweets. This will allow them to share their brief updates with the other Twitter users. Additionally, users can subscribe to other Twitter users' accounts (i.e., follow them on Twitter) to receive a personalised live stream of tweets of these individuals. Users can use a hashtag sign (\#) to categorise keywords and to help users locate the tweets easily. This method also allows users to identify and join conversations on similar topics. Furthermore, users can direct a public post to a specific Twitter user by adding the at sign (@) before the Twitter user's username. To keep the conversation going, Twitter users could reply to another users' posts or could repost someone's post. This act of reposting someone else's post is termed as re-tweet in the language of Twitter. Users can interact and collaborate virtually with other Twitter users across the globe by undertaking the following acts on Twitter: tweeting, following other users' profiles, searching for hashtags, replying to tweets, and retweeting other users’ posts (Java et al., 2007).

\section{Pedagogical use of Twitter}

Microblogging tools can be incorporated into classroom learning activities to facilitate learning. This provides a digital, flexible, and an open learning environment for students, especially in the higher education setting. This mode of learning goes beyond the traditional classroom environment (Evans, 2014). Twitter has been empirically used as a pedagogical tool across different disciplines and settings (Dunlap \& Lowenthal, 2009; Krutka et al., 2017; Luo, 2015, 2016; Selwyn \& Stirling, 2016). Researchers in the past have reported that microblogging could be used to share resources instantly with the learners. Instructors can employ microblogging to share and exchange ideas and insights with the learners in a systematic and timely manner (Click \& Petit, 2010; Hansen, 2011; Thames, 2009). Specifically, instructors and educators can use Twitter as a backchannel to provide just-in-time feedback to the learners, make comments, and pose and answer questions parallel to the main channel of instruction (Cronin, 2011; Kimmons \& Veletsianos, 2016; Li \& Greenhow, 2015; Ross, Terras, Warwick, \& Welsh, 2011). Backchannel communication could be employed to accomplish the following academic goals: to provide examples, to identify errors, to afford student note taking, and to object to or to disapprove something. Instructors could use backchannel communication to conduct private conversations with the students, rather than engaging in whispered private conversations with them in class. They could also debrief students and review the materials with them after class (Cronin, 2011).

Previous researchers have studied Twitter integration and have found support for its use to enhance active learner engagement (Kassens-Noor, 2012), learner-content interaction (Luo, 2015; Domizi, 2013; Munoz et al., 2014), learner-learner interactions (Dunlap \& Lowenthal, 2009; Ebner, 2009; Hsu \& Ching, 2012; Perifanou, 2009), learner-instructor interaction (Prestridge, 2014; McArthur \& Bostedo-Conway, 2012), and academic achievement (Junco, Heiberger, \& Loken, 2011; Kim et al., 2015; Van Vooren \& Bess, 2013). When Twitter is used as a knowledge transmitter, it provides instant feedback to the learners and informs them beyond their individual social networks. Twitter's affordances allow students to become active learners and strengthen their creation, application, and retention of knowledge (Kassens-Noor, 2012). Additionally, a study by Junco et al. (2011) reported that the experimental group that used Twitter for 
education purposes had higher grades than the ones who did not use it. This is because, Twitter-supported activities helped create a dynamic learning community for students where they could collaboratively work on projects and provide emotional support to their peers.

Among the studies that identified varying uses and effects of Twitter integration, a few studies examined the methods of using Twitter to promote reflection and discussion (Ebner \& Maurer, 2009; Wright, 2010). It is important to have students actively reflect on readings to ensure that they understand the concepts that are encapsulated. A common practice in higher education is to have students write a response to a question that is posted in a discussion board within a learning management system, such as Blackboard (Ma, Friel, \& Xing, 2014). However, the extensive use of discussion posts in an LMS may make the learning activity monotonous and futile for students. Prior research has indicated that teachers and instructional designers may need to improve Blackboard discussion board to make the peer-to-peer and peer-to-instructor interactions more convenient and accessible (Loncar, Barrett, \& Liu, 2014; Ma et al., 2014). Compared to the Blackboard discussion board, the use of Twitter, especially via mobile devices, enables users to quickly post and share new messages with no temporal or geographical constraints. We labeled this activity a Quickwrite activity in this study. This method of information exchange is instantaneously archived online. The ability to post on another user's page, and to review and revisit the posts potentially leverages instantaneous communication among peers.

Two studies proposed Twitter's advantages in promoting reflection. Wright (2010) investigated how Twitter supports students' self-reflective practices. The researcher found that students who used Twitter valued the everyday contact that they had with a Twitter-enabled community and they also felt less isolated. Additionally, students reported feeling forced to think more in-depth about the content and felt compelled to write in a clear and concise manner. Taking a microblogging approach fosters students to develop their thoughts and to immediately document them. It also enables them to make more personal and critical statements (Ebner \& Maurer, 2009). The researchers also found that microblogging allowed student to continuously be engaged in the task and thereby, helped them generate deeper level of reflection. Overall, employing the microblogging approach helps learners to engage in writing and involves them in a deep cognitive process that fosters learning.

Researchers also reported challenges and concerns in using Twitter. For example, researchers often found that without instructor mandate, only a limited number of learners actively participated in the act of microblogging whereas, the rest remained inactive (Antenos-Conforti, 2009; Cohen \& Duchan, 2012; Kop, 2011). The lack of voluntary use of Twitter may have been caused by the unfamiliarity of the tool (Lin, Hoffman, \& Borengasser, 2013; Welch \& Bonnan-White, 2012). Previous studies have also found that some participants perceived the use of Twitter as a distraction in the classroom (Andrade, Castro, \& Ferreira, 2012; Rinaldo, Tapp, \& Laverie, 2011). According to Ebner et al. (2009), the 140-character limit potentially harms the quality of dialogue. The tweets analysed in their study were found to be exclusively social in nature. Therefore, the researchers believed that only trivial and arbitrary information exchange was attained during the activity. In Cohen and Duchan (2012) study, students perceived that 140 characters limits meaningful information exchange to occur. Thoms (2012) further enunciated this challenge by labeling Twitter as “a broadcasting technology” (p. 191).

\section{Purpose of study}

Though research on microblogging in education is still at its early stage, researchers have identified various positive effects of integrating Twitter into teaching and learning (Gao et al., 2012; Tang \& Hew, 2017). Employing Twitter as a microblogging approach has positive effects on students' engagement, on their interactions with peers, course content, and the instructor, and on their academic achievements. It was found that Twitter-supported activities help create a collaborative environment where students can share and reflect on their thoughts and ideas and on that of their peers', which in turn, leads to deep cognitive processing of the content information. Twitter has also been found to promote students to reflect and write in a clear and concise manner. However, some researchers have reported that due to the word limit in Twitter, students are unable to have meaningful exchange of information. Therefore, there is some discrepancy regarding the effective use of Twitter to generate exchange of quality reflections. The purpose of this study is to address the paucity of research on the types of knowledge that Twitter-supported activities promote. The questions guiding this study are: 
1. How did students participate in Twitter-supported activity? Specifically, what general participation patterns were observed on Twitter versus Blackboard discussion forum in terms of number of post, number of participation, duration of participation?

2. What types of knowledge were manifested when Twitter was used to reflect on course readings?

3. How did students perceive Twitter-supported reflective learning activities?

\section{Method}

In this study, we employed a case study design to investigate the types of knowledge that Twitter-supported activities promote. This method was selected to help us conduct an in-depth examination of data over a long period of time. In this type of study, the case itself is either unique or complex in its own nature, or both (Yin, 2008). We also utilised comparative analysis technique to cross-analyse data from two cases of discrete and commensurable dimensions to identify the similarities, differences, and patterns.

\section{Participants}

Thirty-eight master's students participated in this study. Of the 38 participants, 18 students were enrolled in the Fall 2015 section, and 20 students were enrolled in the Spring 2015 section. All participants were enrolled in a teacher preparation program at a mid-sized, urban public university. Each class was relatively evenly divided by sex, with male students representing $52 \%$ of the sample population. The majority of students were between the ages of 18 to 35 years. Approximately $75 \%$ of the students reported their preperception of social media use as favorable.

\section{Instructional context}

The study was conducted in an online asynchronous masters-level course. The goal of this course was to provide educators with foundational information on effective technology integration in PK-12. Blackboard Learn 9.1 was the sole learning management system in which all instructional materials and activities were housed. Over a 10-week period of a 13-week course, participants were required to contribute to discussion and reflection activities by writing a weekly Blackboard discussion forum post in response to question prompts that the instructor posed in relation to the readings. This discussion activity compelled students to show what they had read and understood from the readings for that week. In Fall 2015, data from an informal, voluntary, mid-semester student opinion survey collected anonymously suggested that students did not enjoy the Blackboard discussion activity. Students were unsure of how much they should write in the discussion forums and felt that they were not read by other students in the class.

The motivation for this study was to improve the Blackboard discussion and reflection activity within this course, to find a platform that best supports students' reflection of content learned, to draw connections to students' prior learning, to enable students to dictate their answers in a succinct and concise manner while making it a more engaging experience for them. In light of such intent, Twitter was chosen as a tool for conducting discussion activities. This tool provided limited writing space (i.e., 140 characters) for students. It also provided a more agile learning environment than Blackboard. Students were also potentially more attracted to this tool. It should be noted that weekly participation in both discussion forums and the Twitter environment was required as part of course participation credit but was only worth $8 \%$ of the class final grade.

\section{Procedure}

Baseline data was collected in Fall 2015 from Blackboard discussion forums. Over the 10-week period, students were asked to show their understanding of the readings by responding to a discussion question in the discussion board. These questions were crafted in a way that the students would need to have completely grasped the readings to be able to properly respond to each question. The students were told that they should only spend 10 minutes responding to the question and that they could refer back to the readings as they write.

In the Spring 2016 class, Twitter was utilised to replace Blackboard discussion forums for the same activity. Participants were informed that involvement in the study was voluntary and that they could choose to opt out of Twitter and use Blackboard instead. The students were informed that their choice of tool (i.e., Twitter 
or Blackboard) would have no effect on their grades. For possible privacy concerns, we informed students that using their existing Twitter account would provide their peers direct access to what they had posted in the past that may be intended privately for friends and family. Due to this, we strongly encouraged students to create a public Twitter account specifically for the class that could later be deactivated at their own discretion. Prior to the commencement of their writing, participants received a brief video introduction to Twitter. This video was posted on Blackboard. The video informed the participants how to navigate and manipulate the medium. While general guidelines and weekly questions remained unchanged from the Fall 2015 semester, students in the Fall 2016 semester were encouraged to keep their tweets succinct, to the point, and accurate. The usage of the course hashtag \#TLED617 was required in each of their tweets. They were also taught to extend the 140-character limit by replying to their own previously published tweets to continue elaborating on their thought. In addition, students were encouraged but not required to add multimedia elements (e.g., pictures and videos) to their text response. Additionally, they were also encouraged to read and comment on their classmates' responses. At the end of the semester, students completed an online survey in which they reported their perceptions of Twitter as a tool in comparison to Blackboard discussion forum and provided an overall feedback by sharing their Twitter-supported learning experience.

\section{Data collection and analysis}

Data sources encompass students' Blackboard discussion forum posts, as well as tweets and survey responses collected only from the Twitter-involved class. Discussion forum posts were cut and pasted directly from Blackboard. We had preconfigured a Twitter archiving Google sheet (TAGS) to automatically query the tweets' content from Twitter Application Programming Interface (API), storing them in a Google spreadsheet format as they were tweeted in real time. All tweets from Twitter that includes the hashtag \#TLED617 were then saved in Google spreadsheets as a dataset source. To reach data completeness and accuracy, we also employed additional mediums to capture identical data. We used NCapture, a web browser extension of NVivo which is a qualitative data analysis computer software package, to verify if tweets were accurately captured. Finally, we validated data from NVivo and TAGS via Twitter's search bar, by visiting each participant's Twitter page to ensure that we captured all data valid for the study.

The end-of-course survey from the Spring 2016 consists of four Likert-scale questions asking participants to report on their actual participation level, overall perception, and views of their learning experience, along with demographical questions. Open-ended questions were also included allowing participants to offer explanations and reasoning behind their ratings, as well as provide comments elaborating on their quantitative ratings. One question, in particular, asked students to reflect on their Twitter experience by comparing it to Blackboard discussion forums, expounding on the merits and difficulties that they perceived from the same discussion and reflection activity on Twitter.

To answer research question 1 , the discussion forum posts and tweets were both analysed quantitatively to provide insights on the participation patterns of student interactions. The quantitative dimension includes: (a) the number of students who participated; (b) the average number of messages each student posted; and (c) the average word length of each posting. To answer research question 2, we took a deductive approach to analyse the tweets based on a set of a priori codes from Luo and Clifton (2017). This coding scheme adopted can be traced back to a few studies in the past based on a revised version of Bloom's taxonomy (Anderson \& Krathwohl, 2001; Blooma, Kurian, Chua, Goh, \& Lien, 2013; Lin et al., 2013). The knowledge dimension represents the type of knowledge ranging from more concrete (i.e., factual) to abstract ones (i.e., metacognitive). The social dimension originates from the notion of social presence focusing on a learner's perception of being present in a community of inquiry (Rourke, Anderson, Garrison, \& Archer, 2001). Both knowledge and social dimension collectively represent the knowledge construction process suited for a social media-supported learning environment. Two researchers coded the tweets independently. After finalising coding, we calculated the percentage and numerical numbers of tweets belonging to each code. Cohen's Kappa inter-rater reliability was .976, which denotes an almost perfect agreement (Gwet, 2014). Coding scheme with examples of tweets from our data are listed in Table 1. To answer research question 3 , we used a descriptive statistical analysis to calculate the means and standard deviations of each survey items and triangulated with students responses to the open-ended questions. We also further analysed open-ended questions using an open-coding approach to develop themes related to research question 3 .

Table 1 
A coding scheme for knowledge construction by tweets

\begin{tabular}{|c|c|c|}
\hline Codes & Indicators & Examples of Tweets \\
\hline KF - knowledge-factual & $\begin{array}{l}\text { Knowledge of terminology } \\
\text { Factual details and elements }\end{array}$ & $\begin{array}{l}\text { The term Digital Age in } \\
\text { education is referring to how } \\
\text { integrated technology has } \\
\text { become into teaching and } \\
\text { student life. \#tled617 }\end{array}$ \\
\hline KC - knowledge-conceptual & $\begin{array}{l}\text { Classification and } \\
\text { categorisation } \\
\text { Generalisations } \\
\text { Knowledge of theories }\end{array}$ & $\begin{array}{l}\text { Creating requires higher level } \\
\text { thinking and understanding. It } \\
\text { will often encapsulate many of } \\
\text { the lower levels of Bloom's. } \\
\text { \#tled617 }\end{array}$ \\
\hline KP - knowledge-procedural & $\begin{array}{l}\text { Criteria for determining when to } \\
\text { use appropriate procedures } \\
\text { Relates to content } \\
\text { Knowledge of techniques } \\
\text { Knowledge of methods } \\
\text { Knowledge of subject-specific } \\
\text { skills }\end{array}$ & $\begin{array}{l}\text { Teachers must know today's } \\
\text { digital technologies, and } \\
\text { understand the drawbacks, in } \\
\text { order to be leading digital } \\
\text { citizens for students.\#tled617 }\end{array}$ \\
\hline $\begin{array}{l}\text { KM - knowledge-meta- } \\
\text { cognitive }\end{array}$ & $\begin{array}{l}\text { Prior knowledge } \\
\text { Orientation to instruction } \\
\text { Strategy towards learning } \\
\text { Self-regulation of learning } \\
\text { Error-checking }\end{array}$ & $\begin{array}{l}\text { According to TIM, my class } \\
\text { would be in the Constructive } \\
\text { Adoption level. This is based on } \\
\text { the fact students are actively } \\
\text { using tools \#TLED617 }\end{array}$ \\
\hline S - social & $\begin{array}{l}\text { Expressions of emotion } \\
\text { Use of humor } \\
\text { Self-disclosure } \\
\text { Quoting others } \\
\text { Complimenting, cohesive } \\
\text { looping } \\
\text { Consensus building }\end{array}$ & $\begin{array}{l}\text { I will often consult my } 14 \text { yo } \\
\text { daughter for help with this } \\
\text { Twitter. Please let me know } \\
\text { when she has me put an OMG } \\
\text { in the wrong place. \#tled617 }\end{array}$ \\
\hline
\end{tabular}

\section{Results}

\section{Participation pattern}

Table 2 presents data on the total number of posts in discussion forums versus on Twitter. In the discussion forum environment, 18 students published a total of 125 posts; while in Twitter, 20 students published 209 tweets in total. It appears that students participated in the Twitter environment more actively than in the discussion forums, referencing the average quantity of posts per person as well as the weekly number of posts.

Table 2

Total amount of Participation

\begin{tabular}{lllll}
\hline & $N$ & $\begin{array}{l}\text { Total \# of } \\
\text { post }\end{array}$ & $\begin{array}{l}\text { \# of posts per } \\
\text { person }\end{array}$ & $\begin{array}{l}\text { \# of post per } \\
\text { week }\end{array}$ \\
\hline Blackboard Discussion forum & 18 & 125 & 6.9 & 12.6 \\
\hline Twitter & 20 & 209 & 10.5 & 14.8 \\
\hline
\end{tabular}

Participation pattern by week

Figure 1 and 2 depict students' participation on discussion forums and Twitter during a 9-week period, spanning weeks 3 to 12 . It appears that participation on discussion forums was at its peak during the first few weeks of the semester. However, participation gradually diminished over time, with a large drop in numbers from week 10 . The consistent ratio between the number of posts and the number of participants suggests that the same participants published the same minimal number of one post per week. Participation in Twitter shows much higher variability in reference to weekly participation as well as the number of tweets versus participants' ratio. Overall, the number of tweets was higher than discussion forum posts. 
However, it appears that there is not a consistent increasing or decreasing pattern. The number of students participating was initially high and dropped slightly with some variability across different weeks. The considerable gap between the number of posts and the number of participants suggests that during certain weeks, some students posted beyond the minimum requirement of one tweet per week.

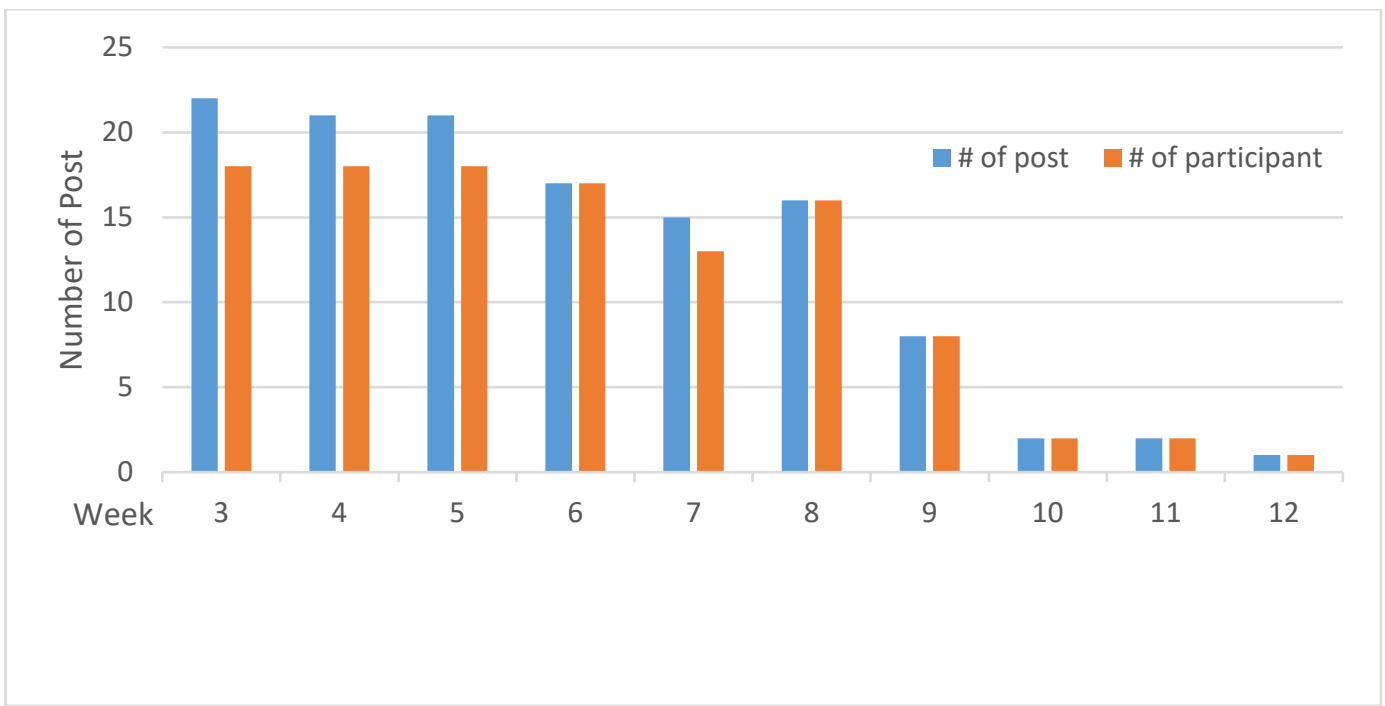

Figure 1. Quantity of posts in discussion forum

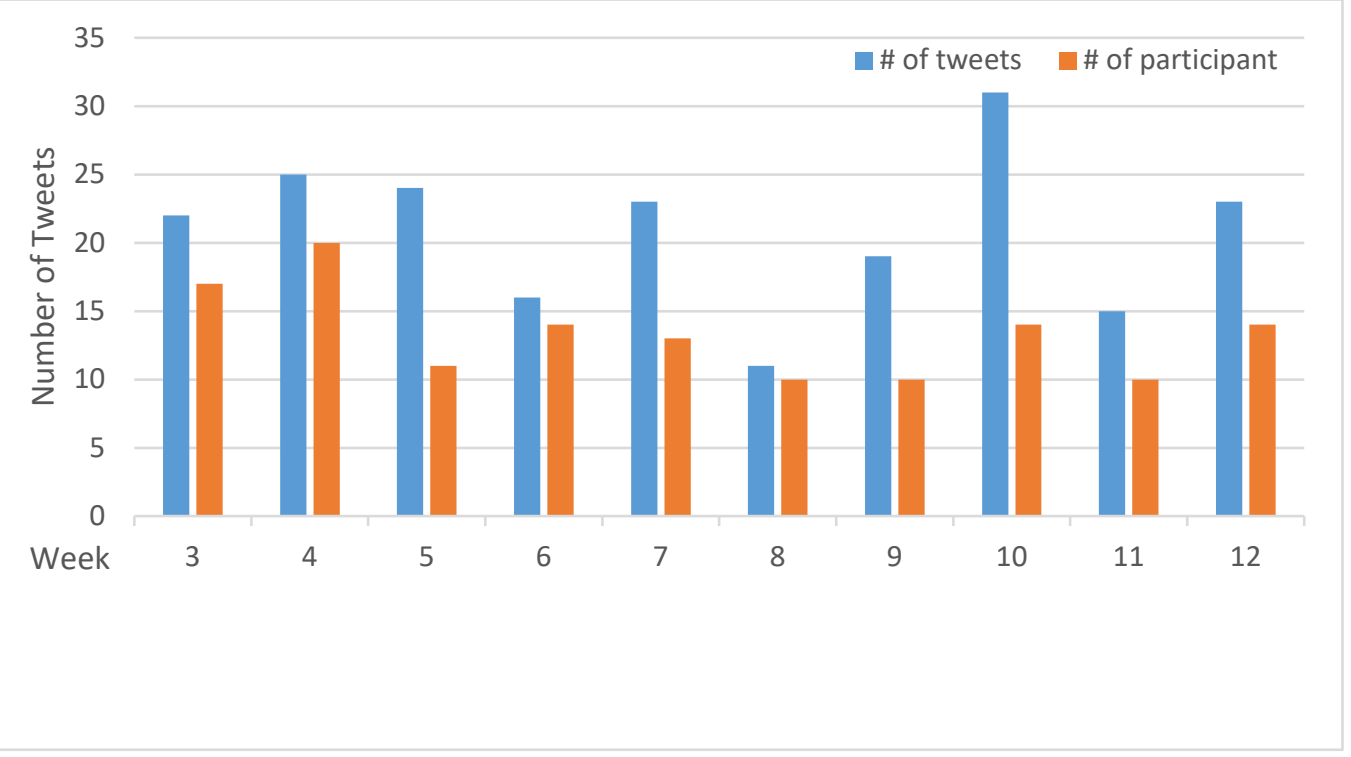

Figure 2. Quantity of tweets

\section{Types of knowledge manifested on Twitter}

According to our data, conceptual knowledge (KC) was the most predominant type of knowledge representing $37 \%$ of the total tweets. Procedural knowledge (KP) came second, representing $29 \%$ of total tweets (Figure 3). The predominance in conceptual and procedural type of knowledge corresponds to the type of questions asked in each week's activity. The manifestation of conceptual knowledge shows evidence for student learning when they were asked to classify, categorise, and generalise knowledge based on their understanding of theories and principles (i.e., "BYOD is cost effective, bridges the gap between school and home learning, more interactive, easy to transport, capacity to store”). The KP element represents learners co-constructing knowledge around the learning content, particularly concerning its procedures, techniques, and methods (i.e., "Teachers can model good technology use by effectively incorporating technology into their lesson plans”). These two types of knowledge, along with factual knowledge at $9 \%$, represent knowledge surrounding the content and its construction. Metacognitive 
knowledge students contained $20 \%$ of the tweets, which demonstrates that students often sought interaction as they self-regulated their learning (i.e., "I will strategically combine community building, modern digital tools, and pedagogy to maximise my students' collaboration”). Interestingly, our data shows little evidence for the social dimension of knowledge construction $(\mathrm{S}=5 \%$ ). This may be explained by the context of this activity where students were not asked to interact or socialise in any live or synchronous setting. Rather, they were asked to focus on reflecting on the learning content.

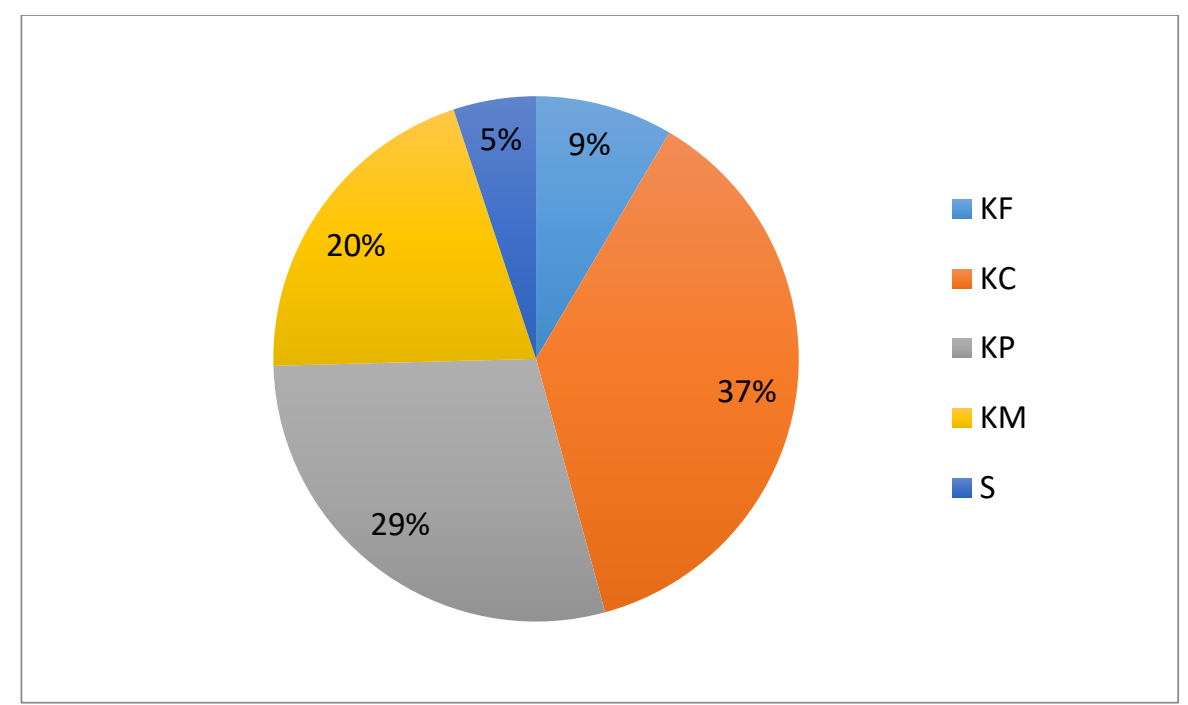

Figure 3. Types of knowledge manifested on Twitter

\section{Student perception}

The surveys first asked students to self-report on how often and in what ways they had used Twitter for the reflection activity. The survey results indicated that the vast majority of students published their tweets in response to the question prompts, while searching and reading their peers' tweets (Table 3). Many also chose to provide comments to their classmates' tweets despite the fact that they may have been anonymous to them, and may have never met face-to-face in the real world.

Table 3

Means and SDs of student ratings on Twitter use

\begin{tabular}{rlccc}
\hline$\#$ & During this class, I have used Twitter to: & $N$ & Mean & $S D$ \\
\hline 1 & write up my response to the discussion question. & 20 & 5.50 & 0.89 \\
2 & search and read my classmates' tweets & 20 & 4.70 & 1.53 \\
3 & provide comments and reply to my peers' tweets. & 20 & 4.10 & 1.68 \\
4 & share my opinion and make them available to the general public & 20 & 4.75 & 1.65 \\
5 & engage in a discussion with my peers. & 20 & 4.10 & 1.55 \\
6 & engage in a discussion with people that I don't know on Twitter. & 20 & 3.05 & 1.47 \\
\hline
\end{tabular}

Note: 1 = strongly disagree; 2 = disagree; 3 = slightly disagree; 4 = slightly agree; 5 = agree; 6 = strongly agree

According to participants' responses to the open-ended question, the vast majority of students reported a positive outlook for Twitter use, with 6 out of the 19 students stating explicitly that they had tweeted every week completing all tweets in response to the Twitter activity. Only one student expressed overt preference to $\mathrm{Bb}$ discussion forums by stating: "I would be much more willing to respond to someone on the Blackboard discussion board than on Twitter." The rich data in these responses sheds light on our observations, displaying the participation pattern in the above column charts (Figures 1 \& 2). The nature of participation tended to become more interactive as the class went on, with some setbacks in the end. As one student put it: "I actually tweeted while writing my own responses and at the beginning of the semester, I started to provide feedback to other classmates but it faded out towards the end.” Students also elaborated on the process of how they generated their own tweets and commented on others' posts in the activity. Many stated that they followed the pattern of first writing their own tweet, then reading others' tweets, and finally replying to a few tweets that interested them. One student noted: 
Each module where a Twitter posting was required, I created my tweet and shared with the community using the \#tled617 hashtag. I would view a few of my classmates' posts and make direct replies to engage conversation. After a few posts, I would "like” a few more posts.

Some students reported that they did not comment on others' tweets as a common practice, but they would read others' tweets since using the hashtag increased visibility. Following comment made by one of the students captures this issue: "I found it was more convenient to read classmates responses since they were all on one page and I didn't have to click on everyone's individual thread”.

Overall, survey results demonstrated that participants highly commended the use of Twitter in the learning activity. Across all survey items designed to elicit their perception on various dimensions, participants expressed favorable views of the use of Twitter as a replacement for Blackboard discussion forums (Table 4). Students enjoyed and achieved a high level of satisfaction with their experience using Twitter for reading reflection. They also expressed a high intent for the prospective reuse of Twitter in discussion environments.

Table 4

Means and SDs of student ratings on overall perception

\begin{tabular}{llccc}
\hline$\#$ & Overall perception & $N$ & Mean & $S D$ \\
\hline 1 & $\begin{array}{l}\text { I enjoyed the use of Twitter as a reading discussion tool. } \\
\text { If given the chance, I am willing to reuse Twitter for discussion } \\
\text { activities. }\end{array}$ & 20 & 4.60 & 1.57 \\
& $\begin{array}{l}\text { I prefer Blackboard discussion forum to Twitter for such reading } \\
\text { discussion and reflection activities. }\end{array}$ & 20 & 3.70 & 1.63 \\
$\quad \begin{array}{l}\text { I am satisfied with my experience using Twitter in the discussion } \\
\text { activity. }\end{array}$ & 20 & 4.80 & 1.58 \\
\hline
\end{tabular}

Note: 1 = strongly disagree; 2 = disagree; 3 = slightly disagree; 4 = slightly agree; 5 = agree; 6 = strongly agree

When asked about the how they specifically perceived their learning experience, participants again reported to have rated it highly across all dimensions (Table 5). The most consistently rated items were: "The Twitter-supported discussion activity helped me articulate my own understanding of the reading material”, "The Twitter-supported discussion activity helped me focus on learning the topic", and "The Twittersupported discussion activity helped enhance critical thinking.” Additionally, many students reported having fun participating in the activity and interacting with classmates that they had never met before.

Table 5

Means and SDs of student ratings on perceived learning experience

\begin{tabular}{|c|c|c|c|c|}
\hline \# & Statements & $N$ & Mean & $S D$ \\
\hline 1 & $\begin{array}{l}\text { The Twitter-supported Quickwrite activity helped me articulate my } \\
\text { own understanding of the reading material. }\end{array}$ & 20 & 5.00 & 1.21 \\
\hline 2 & $\begin{array}{l}\text { The Twitter-supported Quickwrite activity helped me focus on } \\
\text { learning the topic. }\end{array}$ & 20 & 4.85 & 1.46 \\
\hline 3 & $\begin{array}{l}\text { The Twitter-supported Quickwrite activity helped enhance critical } \\
\text { thinking. }\end{array}$ & 20 & 4.80 & 1.28 \\
\hline 4 & $\begin{array}{l}\text { I had a lot of fun participating in Twitter-supported Quickwrite } \\
\text { activity. }\end{array}$ & 20 & 4.50 & 1.67 \\
\hline 5 & $\begin{array}{l}\text { The Twitter-supported Quickwrite activity helped me to interact } \\
\text { with my classmates. }\end{array}$ & 20 & 4.45 & 1.43 \\
\hline 6 & I was highly involved in the Twitter-supported Quickwrite activity. & 20 & 4.40 & 1.43 \\
\hline
\end{tabular}

Note: 1 = strongly disagree; 2 = disagree; 3 = slightly disagree; 4 = slightly agree; 5 = agree; 6 = strongly agree

\section{Themes from open-ended questions}

Students' responses to open-ended questions provided insight into their perception of the Twitter-based learning experience. First, an overwhelming majority (18 out of 20) students reported that they enjoyed the experience. This reconfirmed and validated our data from the survey response. About half of the students 
commended Twitter for its ease-of-use; a defining attribute that they perceived. It was easy for students to review their peers’ posts in a coherent format, interacting with them using the @ symbol. Being a userfriendly, quick, and convenient lightweight tool that one can access any time, and from anywhere is a contributing factor that prompted students to favor the use of Twitter. Some students reported that they enjoyed accessing it from their phone seamlessly at any time to either read or review the tweets. One student stated: "It also provided an easy way I could check classmate responses straight from my phone rather than having to wait to log in to Blackboard.” The reported benefits also included Twitter's global outreach, flexibility, as well as a variety of functionally diverse features that are conducive to cultivating interactivity and connectivity (@ symbol, “like” function, and “reply to” and “retweet” button).

Compared to Blackboard discussion forums, students found Twitter to be "easier and faster to follow conversations” and "easy to find other opinions to review and discuss.” One student commented:

Twitter was a quick and easy way to post our responses, and more importantly, see our classmates' responses all in one place in our Twitter streams, versus in Blackboard where you have to click on each post to read and respond. Also the liked button was a quick way to give immediate feedback.

A few students also commented that because they had been active on Twitter prior to the assignment, it was easy for them to remember doing the assignment, integrating it into their routine. Contrastingly, two students preferred Blackboard discussion forums because they used it for other courses, stating: "having Twitter too just added another thing to my list of websites to check." One student stated: "Blackboard is checked regularly as a student. It is something that is engrained in you early on in college. If you do not regularly use Twitter it is more difficult to get the habit of doing so."

Students alluded that they see both benefits and constraints with the 140-character limit, with more students seeing it as a benefit. In most cases, they recognised that they were given less space to write lengthier text in the Twitter environment; thus, demanding that the content they published is succinct, concise, to-thepoint, thoughtful and critical. As one participant put it:

Twitter forces a good understanding of the topic because you have to constrict your thinking to so few words, whereas in Blackboard which gives you the ability to write openly, I have seen more of my classmates and even myself ramble on and on without even really addressing the topic.

Another student summed up his experience in this manner:

Using Twitter as a reading discussion tool was thoroughly enjoyable. I would very much like to use it again in future classes for discussion activities. While the Blackboard discussion forum is a great conduit for scholarly discussion, I personally found Twitter to be more efficient and enjoyable. I am very satisfied with my experiences using Twitter for Quick Write activities. I do not have any complaints about it.

\section{Discussion and conclusion}

Our data showed an overall positive perception toward the integration of Twitter to support reflection on learning content alongside active participation. The results of this study indicate that students who used Twitter to participate in the class discussion activities posted more posts or tweets per week compared to the students who used the Blackboard discussion forums. Students in the Twitter group had a relatively consistent participation in the discussion activities across the weeks, with no consistent increase or decrease pattern in participation identified. Whereas, participation in the Blackboard discussion form significantly diminished by week 10. This shows that Twitter was successful in keeping the learners engaged in the discussion activities for a prolonged period compared to Blackboard. Students perceived the use of Twitter favorably. They used it to post their reflective responses to the discussion prompts, search and read their peers' responses, as well as to reply to their peers' responses. Students perceived Twitter to be helpful in articulating their understanding of the course materials and in enhancing critical thinking. They also reported that they had fun using Twitter as a discussion tool for reflective learning. Therefore, we conclude that Twitter was effective in increasing perceived learner-content and learner-learner interactivity along 
with engagement. This aligns with the findings from the prior literature (Domizi, 2013; Dunlap \& Lowenthal, 2009; Ebner, 2009; Hsu \& Ching, 2012; Munoz et al., 2014, Perifanou, 2009).

As compared to Blackboard discussion forum, Twitter may be advantageous in promoting reflective learning in the following aspects. One of the benefits of using Twitter as a reflective learning tool for discussion is that it affords sharing of personal reflections and reviewing others' responses in an easy and timely manner. Prior research demonstrated that in threaded discussion forums it is difficult to promote interactive conversations and receive timely feedback (Curtis \& Lawson, 2001; Gao, Zhang, \& Franklin, 2013; Thomas, 2002). Contradictory to this, the present study found that Twitter's easy-to-navigate interface, the use of hashtag, and the search functions enabled students to easily post, read and quickly respond to other students' tweets as they did not have to invest a lot of time or mental resources in dealing with the threaded discussion format in Blackboard that is often perceived as clunky or cumbersome. Many students in our study may have perceived the 140-character word limit as a constraint that forced them to organise their thoughts in a meaningful manner. This in turn, prompted students to reflect more deeply and write more concisely about the material in their posts. Arguably, the results of this study imply that "with the 140-character limit on messaging, Twitter is compatible with the way people think and work within the contexts of being brief, clear, and concise in writing and communication” (Davis \& Yin, 2013, p. 50). Therefore, it appears to be effective in promoting students' reflecting learning.

We provide several implications for educational practitioners. First, it is critical to take students' prior perceptions and experience into account simply because not all students will perceive Twitter's functionalities the same way. It would be worth considering to provide additional training for novice Twitter users whenever necessary and to monitor their learning progress. Second, the integration of Twitter should fit the purpose of the learning activity. In other words, the pedagogy used in the Twitter activity should be well aligned with the learning goals and objectives in a particular content area. Since Twitter is originally not an educational tool, educators need to be creative in designing innovative activities that serve their varying instructional purposes and optimise Twitter's unique affordances such as promoting brief, clear, and concise in writing and communication. Lastly, it goes without saying that instructors play a major role when undertaking using Twitter as an educational tool. In order for these tools to be effective, instructors need to set clear rules, provide ongoing guidance, and set clear expectations to regulate the use of the tools in order to reach the desired learning purposes.

\section{Limitations and recommendations for future research}

Methodological limitations for this study include a small sample size, limited data and reporting methods, and curtailed duration of implementation. The modest sample size and convenience sampling made the results suggestive and less indicative of varying populations in various contexts. Consequently, the use of convenient sampling limits the study to only speak for participants in the specific teacher preparation program settings. We attained survey data from the Twitter case. However, we were unable to collect identical types of data from the blackboard discussion forum group. This resulted in some level of data nonequivalence. Further studies are warranted to provide a more robust understanding of the type of knowledge that Twitter-supported activities promote in a short 10-week course. There is a possibility that the results could have been affected by the novelty effect. That is, students' performance (i.e., participation) may have increased because the students were introduced to a new tool that they could use for the class and not because one tool was better than the other. To ensure that the results were not reflective of the novelty effect, future researchers must conduct longitudinal studies to further investigate the use of Twitter as a discussion tool to facilitate reflective learning. It is also reasonable to believe that students who may have used Twitter before or who are active users (i.e., experts) may differ in the participation performance compared to the novice users. Therefore, future researchers could investigate if prior experience using Twitter affects students’ participation in the reflective learning activities. 


\section{References}

Anderson, L. W., \& Krathwohl, D. R. (2001). A taxonomy for learning, teaching, and assessing: A revision of Bloom's taxonomy of educational objectives. New York, NY: Longman.

Andrade, A., Castro, C., \& Ferreira, S. A. (2012). Cognitive communication 2.0 in higher education: To tweet or not to tweet? Electronic Journal of E-Learning, 10(3), 293-305. Retrieved from https://eric.ed.gov/?id=EJ985431

Antenos-Conforti, E. (2009). Microblogging on Twitter: Social networking in intermediate Italian classes. In L. Lomicka, \& G. Lord (Eds.), The next generation: Social networking and online collaboration in foreign language learning (pp. 59-90). San Marcos, TX: CALICO Publications.

Bahner, D. P., Adkins, E., Patel, N., Donley, C., Nagel, R., \& Kman, N. E. (2012). How we use social media to supplement a novel curriculum in medical education. Medical Teacher, 34(6), 439-444. https://doi.org/10.3109/0142159X.2012.668245

Blessing, S. B., Blessing, J. S., \& Fleck, B. K. B. (2012). Using Twitter to reinforce classroom concepts. Teaching of Psychology, 39(4), 268-271. https://doi.org/10.1177/0098628312461484

Blooma, M. J., Kurian, J. C., Chua, A. Y. K., Goh, D. H. L., \& Lien, N. H. (2013). Social question answering: Analyzing knowledge, cognitive processes and social dimensions of micro-collaborations. Computers \& Education, 69, 109-120. https://doi.org/10.1016/j.compedu.2013.07.006

Click, A., \& Petit, J. (2010). Social networking and Web 2.0 in information literacy. The International Information \& Library Review, 42(2), 137-142. https://doi.org/10.1016/j.iilr.2010.04.007

Cohen, A., \& Duchan, G. (2012). The usage characteristics of Twitter in the learning process. Interdisciplinary Journal of E-Learning and Learning Objects, 8(1), 149-163. Retrieved from https://eric.ed.gov/?id=EJ1058346

Cronin, J. J. (2011). The classroom as a virtual community: an experience with student backchannel discourse. Business Education Innovation Journal, 3(2), 56-65.

Curtis, D. D. \& Lawson, M. J. (2001). Exploring collaborative online learning. Journal of Asynchronous Learning Networks, 5(1), 21-34. Retrieved from https://pdfs.semanticscholar.org/30b5/b12979f7b12c758c997509ec82e46abfeea5.pdf

Davis, L., \& Yin, L. R. (2013). Teaching writing with Twitter: An exploration of social media use in enhancing business communication skills. The Journal of Research in Business Education, 55(1), 3652. Retrieved from https://search.proquest.com/openview/157a2647221bd5ca4cc2a1f8ea5ef306/1?pqorigsite $=$ gscholar\&cbl $=34490$

Domizi, D. P. (2013). Microblogging to foster connections and community in a weekly graduate seminar course. TechTrends, 57(1), 43-51. https://doi.org/10.1007/s11528-012-0630-0

Dunlap, J. C., \& Lowenthal, P. R. (2009). Tweeting the night away: Using Twitter to enhance social presence. Journal of Information Systems Education, 20(2), 129-155. Retrieved from https://eric.ed.gov/?id=EJ844214

Ebner, M. (2009). Interactive lecturing by integrating mobile devices and micro-blogging in higher education. Journal of Computing and Information Technology, 17(4), 371-381. https://doi.org/10.2498/cit.1001382

Ebner, M., \& Maurer, H. (2009). Can weblogs and microblogs change traditional scientific writing? Future Internet, 1(1), 47-58. https://doi.org/10.3390/fi1010047

Evans, C. (2014). Twitter for teaching: Can social media be used to enhance the process of learning? Twitter for teaching. British Journal of Educational Technology, 45(5), 902-915. https://doi.org/10.1111/bjet.12099

Gao, F., Luo, T., \& Zhang, K. (2012). Tweeting for learning: A critical analysis of research on microblogging in education published in 2008-2011. British Journal of Educational Technology, 43(5), 783-801. https://doi.org/10.1111/j.1467-8535.2012.01357.x

Gao, F., Zhang, T., \& Franklin, T. (2013). Designing asynchronous online discussion environments: Recent progress and possible future directions. British Journal of Educational Technology, 44(3), 469-483. https://doi.org/10.1111/j.1467-8535.2012.01330.x

Greenhow, C., \& Askari, E. (2017). Learning and teaching with social network sites: A decade of research in K-12 related education. Education and Information Technologies, 22(2), 623-645. Retrieved from https://eric.ed.gov/?id=EJ1132101

Greenwood, S., Perrin, A., \& Duggan, M. (2016). Social media update 2016. Pew Research Center. Retrieved from http://www.pewinternet.org/2016/11/11/social-media-update-2016/

Gwet, K. L. (2014). Handbook of inter-rater reliability: The definitive guide to measuring the extent of agreement among raters. Gaithersburg, MD: Advanced Analytics, LLC. 
Hansen, D. L. (2011). Exploring social media relationships. On the Horizon, 19(1), 43-51. https://doi.org/10.1108/10748121111107726

Hsu, Y. C., \& Ching, Y. H. (2012). Mobile microblogging: Using Twitter and mobile devices in an online course to promote learning in authentic contexts. The International Review of Research in Open and Distance Learning, 13(4), 211-227. http://dx.doi.org/10.19173/irrodl.v13i4.1222

Java, A., Song, X., Finin, T., \& Tseng, B. (2007). Why we Twitter: Understanding microblogging usage and communities Proceedings of the 9th WebKDD and 1st SNA-KDD 2007 workshop on Web mining and social network analysis (pp. 56-65). New York, NY: ACM.

Junco, R., Heiberger, G., \& Loken, E. (2011). The effect of Twitter on college student engagement and grades. Journal of Computer Assisted Learning, 27(2), 119-132. https://doi.org/10.1111/j.13652729.2010.00387.X

Kassens-Noor, E. (2012). Twitter as a teaching practice to enhance active and informal learning in higher education: The case of sustainable tweets. Active Learning in Higher Education, 13(1), 9-21. https://doi.org/10.1177/1469787411429190

Kim, Y., Jeong, S., Ji, Y., Lee, S., Kwon, K. H., \& Jeon, J. W. (2015). Smartphone response system using Twitter to enable effective interaction and improve engagement in large classrooms. IEEE Transactions on Education, 58(2), 98-103. https://doi.org/10.1109/TE.2014.2329651

Kimmons, R., \& Veletsianos, G. (2016). Education scholars' evolving uses of twitter as a conference backchannel and social commentary platform. British Journal of Educational Technology, 47(3), 445464. https://doi.org/10.1111/bjet.12428

Kop, R. (2011). The challenges to connectivist learning on open online networks: Learning experiences during a massive open online course. The International Review of Research in Open and Distance Learning, 12(3), 19-38. Retrieved from http://www.irrodl.org/index.php/irrodl/article/view/882/1689

Krutka, D., Nowell, S., \& Whitlock, A. M. (2017). Towards a social media pedagogy: Successes and shortcomings in educative uses of Twitter with teacher candidates. Journal of Technology and Teacher Education, 25(2), 215-240. Retrieved from https://eric.ed.gov/?id=EJ1141211

Li, J., \& Greenhow, C. (2015). Scholars and social media: tweeting in the conference backchannel for professional learning. Educational Media International, 52(1), 1-14. https://doi.org/10.1080/09523987.2015.1005426

Lin, M. F. G., Hoffman, E. S., \& Borengasser, C. (2013). Is social media too social for class? A case study of Twitter use. TechTrends, 57(2), 39-45. Retrieved from https://link.springer.com/article/10.1007/s11528-013-0644-2

Loncar, M., Barrett, N. E., \& Liu, G. Z. (2014). Towards the refinement of forum and asynchronous online discussion in educational contexts worldwide: Trends and investigative approaches within a dominant research paradigm. Computers \& Education, 73, 93-110.

http://dx.doi.org/10.1016/j.compedu.2013.12.007

Luo, T. (2015). Instructional guidance in microblogging-supported learning: insights from a multiple case study. Journal of Computing in Higher Education, 27(3), 173-194. Retrieved from https://link.springer.com/article/10.1007/s12528-015-9097-2

Luo, T. (2016). Enabling microblogging-based peer feedback in face-to-face classrooms. Innovations in Education and Teaching International, 53(2), 156-166. https://doi.org/10.1080/14703297.2014.995202

Luo, T., \& Clifton, L. (2017). Examining collaborative knowledge construction in microblogging-based learning environments. Journal of Information Technology Education: Research, 16, 365-390. Retrieved from https://eric.ed.gov/?id=EJ1161795

Ma, Y., Friel, C., \& Xing, W. (2014, June). Instructional activities in a discussion board forum of an eleaning management system. Proceedings of the International Conference on Human-Computer Interaction (pp. 112-116). Retrieved from https://link.springer.com/chapter/10.1007/978-3-31907854-0_20\#citeas

McArthur, J. A., \& Bostedo-Conway, K. (2012). Exploring the relationship between student-instructor interaction on Twitter and student perceptions of teacher behaviors. International Journal of Teaching and Learning in Higher Education, 24(3), 286-292. Retrieved from https://eric.ed.gov/?id=EJ1000682

Mills, K. A., \& Chandra, V. (2011). Microblogging as a literacy practice for educational communities. Journal of Adolescent \& Adult Literacy, 55(1), 35-45. https://doi.org/10.1598/JAAL.55.1.4

Munoz, L.,R., Pellegrini-Lafont, C., \& Cramer, E. (2014). Using social media in teacher preparation Programs: Twitter as a means to create social presence. PennGSE Perspectives on Urban Education, 11(2), 57-69. Retrieved from https://www.urbanedjournal.org/archive/volume-11-issue-2-summer2014/using-social- 
Perifanou, M., A. (2009). Language micro-gaming: Fun and informal microblogging activities for language learning. Communications in Computer and Information Science, 49, 1-14. https://doi.org/10.1007/978-3-642-04757-2_1

Pollard, E. A. (2014). Tweeting on the backchannel of a jumbo-sized lecture hall: Maximizing collective learning in a world history survey. The History Teacher, 47(3), 329-354. Retrieved from http://www.societyforhistoryeducation.org/pdfs/M14_Pollard.pdf

Prestridge, S. (2014). A focus on students' use of Twitter-their interactions with each other, content and interface. Active Learning in Higher Education, 15(2), 101-115. Retrieved from https://eric.ed.gov/?id=EJ1026952

Richardson, J., Grose, J., Nelmes, P., Parra, G., \& Linares, M. (2015). Tweet if you want to be sustainable: A thematic analysis of a Twitter chat to discuss sustainability in nurse education. Journal of Advanced Nursing, 72(5), 1086-1096. https://doi.org/10.1111/jan.12900

Ricoy, M. C., \& Feliz, T. (2016). Twitter as a learning community in higher education. Journal of Educational Technology \& Society, 19(1), 237-248. Retrieved from https://www.jstor.org/stable/pdf/jeductechsoci.19.1.237.pdf?seq=1\#page_scan_tab_contents

Rinaldo, S. B., Tapp, S., \& Laverie, D. A. (2011). Learning by tweeting: using Twitter as a pedagogical tool. Journal of Marketing Education, 33(2), 193-203. https://doi.org/10.1177/0273475311410852

Ross, C., Terras, M., Warwick, C., \& Welsh, A. (2011). Enabled backchannel: Conference Twitter use by digital humanists. Journal of Documentation, 67(2), 214-237. https://doi.org/10.1108/00220411111109449

Rourke, L., Anderson, T., Garrison, D. R., \& Archer, W. (2001). Methodological issues in the content analysis of computer conference transcripts. International Journal of Artificial Intelligence in Education, 12, 8-22. Retrieved from https://telearn.archives-ouvertes.fr/hal-00197319/

Selwyn, N., \& Stirling, E. (2016). Social media and education ... now the dust has settled. Learning, Media and Technology, 41(1), 1-5. https://doi.org/10.1080/17439884.2015.1115769

Shah, N., Shabgahi, S., \& Cox, A. M. (2016). Uses and risks of microblogging in organisational and educational settings. British Journal of Educational Technology, 47(6), 1168-1182. https://doi.org/10.1111/bjet.12296

Tang, Y., \& Hew, K. F. (2017). Using Twitter for education: Beneficial or simply a waste of time? Computers \& Education, 106, 97-118. https://doi.org/10.1016/j.compedu.2016.12.004

Thames, G. (2009). Twitter as an educational tool. Journal of Child and Adolescent Psychiatric Nursing, 22(4), 235-235. https://doi.org/10.1111/j.1744-6171.2009.00208.x

Thomas, M. J. W. (2002). Learning within incoherent structures: the space of online discussion forums. Journal of Computer Assisted Learning, 18, 351-366. https://doi.org/10.1046/j.02664909.2002.03800.x

Thoms, B. (2012). Student perceptions of microblogging: Integrating Twitter with blogging to support learning and interaction. Journal of Information Technology Education, 11, 179-197. Retrieved from http://jite.org/documents/Vol11/JITEv11IIPp179-197Thoms1109.pdf

Trust, T., Krutka, D. G., \& Carpenter, J. P. (2016). “Together we are better”: Professional learning networks for teachers. Computers \& Education, 102, 15-34. https://doi.org/10.1016/j.compedu.2016.06.007

Van Vooren, C., \& Bess, C. (2013). Teacher Tweets improve achievement for eighth grade science students. Journal of Education, Informatics \& Cybernetics, 11(1), 33-36. Retrieved from http://www.iiisci.org/journal/CV\%24/sci/pdfs/HHB348DV.pdf

Welch, B. K., \& Bonnan-White, J. (2012). Twittering to increase student engagement in the university classroom. Knowledge Management \& E-Learning: An International Journal (KM\&EL), 4(3), 325345. Retrieved from http://www.kmel-journal.org/ojs/index.php/onlinepublication/article/viewArticle/201

Wright, N. (2010). Twittering in teacher education: Reflecting on practicum experiences. Open Learning: The Journal of Open, Distance and e-Learning, 25(3), 259-265. https://doi.org/10.1080/02680513.2010.512102

Yin, R. K. (2008). Case study research: Design and methods. Thousand Oaks, CA: Sage Publications.

Corresponding author: Tian Luo, tluo@odu.edu

Australasian Journal of Educational Technology (c) 2019.

Please cite as: Luo, T., Shah, S. J., \& Crompton, H. (2019). Using Twitter to support reflective learning in an asynchronous online course. Australasian Journal of Educational Technology, 35(3), 31-44. https://doi.org/10.14742/ajet.4124 